\title{
Open-loop voltage control voltage source inverter for a linear load \& non-linear load
}

\author{
Akhilesh Sharma ${ }^{1}$, Neeraj Kumar ${ }^{2}$, Gunjan Gupta ${ }^{3}$ \\ ${ }^{1}$ NERIST, Nirjuli, Arunachal Pradesh, India \\ ${ }^{2}$ DIET, Rishikesh, Uttarakhand, India \\ ${ }^{3}$ Invertis University, Bareilly, U.P., India \\ Email address: \\ akhil_ful@rediffmail.com (A. Sharma),neer_81@rediffmail.com (N. Kumar), gunjan.g@invertis.org (G. Gupta)
}

\section{To cite this article:}

Akhilesh Sharma, Neeraj Kumar, Gunjan Gupta. Open-Loop Voltage Control Voltage Source Inverter for a Linear Load \& Non-Linear Load. Journal of Electrical and Electronic Engineering. Special Issue: Sustainable and Renewable Energies and Systems.

Vol. 3, No. 1-1, 2015, pp. 13-21. doi: 10.11648/j.jeee.s.2015030101.12

\begin{abstract}
The conventional sources of energy are limited which are unable to meet the demand. There is always need of generation of electrical energy worldwide, may be in terms of few kilowatts to hundreds of kilowatts. The power requirement at the domestic level is terms of few kilowatts so there should be a way to meet the electrical demand at domestic level during load shading or fault. A subtitle to this could be a Voltage controlled voltage source inverters (VCVSIs). Now a day, such inverters are widely used in many applications like power supplies, power quality controllers, renewable energy, marine and military to meet the demand. Wherever an ac supply is need from a DC source, such inverters may be used. They are the heart and soul of converting DC into an ac source. Hence, such inverters should be designed so that they are robust and efficient. Inverter models can be design and simulated with software like Matlab Simulink to check suitability of inverter before implementing the hardware. Loads at the domestic level may be linear or non- linear hence a simple approach to design a voltage source inverter using open loop is presented in this paper.
\end{abstract}

Keywords: Voltage Controlled Voltage Source Inverters, MOSFET, Thyristors, Open-Loop Control System

\section{Introduction}

Exponential growth of population and industries has lead to more demand of electrical power. The generating stations are unable to meet the power demand. Even the frequent power failure, hampers the living of people in cities, towns and villages. There is misbalance in utilization and generation of electrical power.

So it has become mandatory to switch engineers to find other alternative to meet so portion of the demand. Nonconventional sources have their own limitations. For example, solar power plant depends on factors like weather condition, altitude and solar radiation etc. If sky is clear, the places located at higher altitude will receive high intensity of solar radiation than the places located at low altitude during the day. The luminous intensity also varies from forenoon to afternoon. Hence, it is difficult to harness electrical energy from such sources at our will. One way to do so is to develop fast switching devices MOSFET, IGBT, BJT and Thyristors etc which help in converting DC into ac source called inverter [1].

A fixed DC source can be converted to ac through an inverter. The function of an inverter is to change a fixed dc input to an ac output voltage of desired magnitude and frequency hence it can be said that the output voltage obtained from the device could be fixed or variable one without change in frequency. A variable output voltage can be obtained by varying the input dc voltage and maintaining the gain of the inverter constant. On the other hand, if the dc input voltage is fixed and it is not controllable, a variable output voltage can be obtained by varying the gain of the inverter, which is normally accomplished by pulse width modulation control within the inverter. [4 and 6].

An ideal inverter should have output voltage exactly similar to a sine wave. But this is not so when a practical inverter is considered. The output voltage wave may be non sinusoidal containing harmonics of different order. This may due to the switching on and off of an inverter. For low- and medium- power applications, square - wave or quasi - square wave voltages may be acceptable; this is not so for high power applications, where low distorted sinusoidal wave 
forms may be accepted. In order to achieve sinusoidal wave of low distortion, the operating speed of power semiconductor devices should be high. Further reduction in harmonic is possible if proper switching technique is applied. [1 and 5].

\section{Principle of Operation of a Single Phase}

The principle of operation depends upon the switching of power electronic devices. Accordingly it can either be half wave or full wave inverter. A half wave inverter is one which requires two choppers whereas a full wave inverter requires four choppers. The former is discussed as under [1 and 6].

\subsection{Half-Wave Inverter}

The principle of single phase half wave inverters is explained on the basis of figure 1 as under:

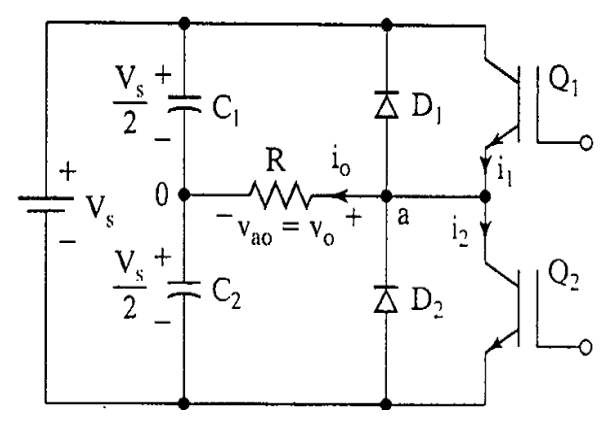

Figure 1. A single phase half wave inverter

A single phase half wave inverter consists of two choppers, say IGBTs in this case. When only one IGBT $\mathrm{Q}_{1}$ is turned on for a time $\mathrm{T}_{0} / 2$, the instantaneous voltage across the load $\mathrm{v}_{0}$ is $\mathrm{V}_{\mathrm{s}} / 2$. If only the IGBT $\mathrm{Q}_{2}$ is turned on for a time $\mathrm{T}_{0} / 2,-\mathrm{V}_{\mathrm{s}} / 2$ appears across the load. The logic circuit should be designed in such a way that both the IGBTs do not turn at a time i.e. if $\mathrm{Q}_{1}$ turn on, $\mathrm{Q}_{2}$ should be off and vice - versa. Figure 2 shows the wave forms for the output voltage and currents with resistive load.

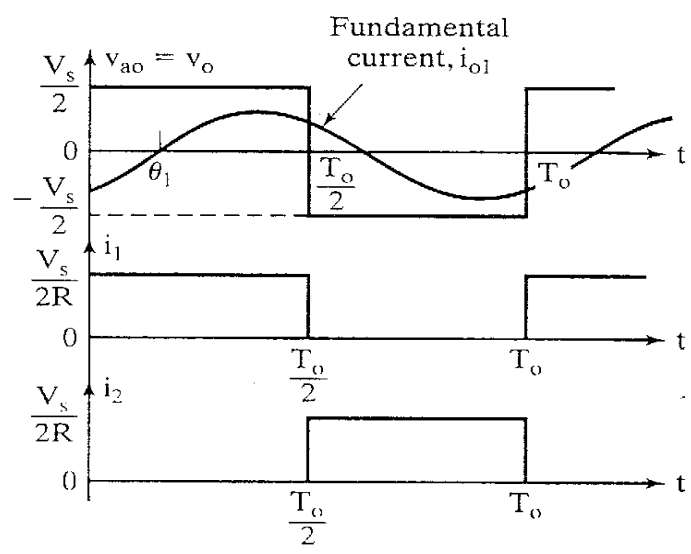

Figure 2. Voltage and current waveform with resistive load
The root- mean- square (rms) output voltage can be found from

$$
\mathrm{V}_{0}=\left(\frac{2}{\mathrm{~T}_{0}} \int_{0}^{\mathrm{T}_{0}} / 2 \frac{\mathrm{V}_{\mathrm{s}}^{2}}{4} \mathrm{dt}\right)^{1 / 2}=\frac{\mathrm{V}_{\mathrm{s}}}{2}
$$

The instantaneous output voltage can be expressed in Fourier series as

$$
\begin{aligned}
& v_{0}=\frac{a_{0}}{2}+\sum_{n=1}^{\infty}\left(a_{n} \cos (n \omega t)+b_{n} \sin (n \omega t)\right) \\
& b_{n}=\frac{1}{\pi}\left[\int_{-\frac{\pi}{2}}^{0} \frac{-V_{s}}{2} d(\omega t)+\int_{0}^{\frac{\pi}{2}} \frac{V_{s}}{2} d(\omega t)\right]=\frac{4 V_{s}}{n \pi}
\end{aligned}
$$

which gives the instantaneous output voltage $v_{0}$ as

$$
v_{0}=\sum_{n=1,3,5 \ldots}^{\infty} \frac{2 V_{s}}{n \pi} \sin n \omega t=0 \quad n 2,4,6 \ldots
$$

where $\omega=2 \pi f_{0}$ is the frequency of output voltage in radians per second. Due to the quarter wave symmetry of the output voltage along the $\mathrm{x}$ - axis, the even harmonics voltages are absent. The fundamental component of the rms output voltage is obtained for $n=1$, so equation (2.2) reduces to

$$
V_{01}=\frac{2 V_{s}}{\sqrt{2} \pi}=0.45 V_{s}
$$

For a highly inductive load, the load current cannot change immediately with the output voltage i.e. if $\mathrm{Q}_{1}$ is turned off at $t=\frac{T_{0}}{2}$, the load current would continue to flow through $\mathrm{D}_{2}$, load, and lower half of the dc source until the current falls to zero. Similarly, when $\mathrm{Q}_{2}$ is turned off at $t=T_{0}$, the load current flows through $\mathrm{D}_{1}$, load, and upper half of the dc source. When either of the diode $\mathrm{D}_{1}$ or $\mathrm{D}_{2}$ conducts, energy is fed back to the dc source and these diodes are known as feedback diodes. Figure 3 shows the load current and conduction intervals of the device for a purely inductive load.

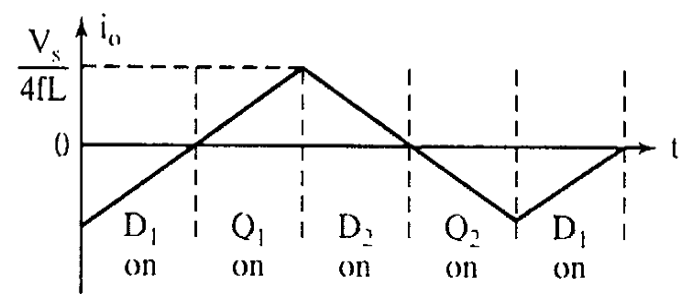

Figure 3. Current waveform with inductive load

IGBTs can be replaced by any other switching devices like MOSFET, BJT, etc as per the requirement. If $t_{\text {off }}$ is the turn off time of a device, there should be a minimum delay time of $t_{d}=\left(t_{\text {off }}\right)$ between the outgoing device and triggering of the next incoming device. Otherwise, short circuit condition would result through the two devices. In order to avoid this condition, the conduction time is reduced. The maximum conduction time of a device would be $t_{o n}=\frac{T_{0}}{2}-t_{d}$.

All practical devices require a certain turn - on and turn off time. 


\subsection{Principle of Operation of a Full-Wave Single Phase Inverter}

A single phase bridge voltage source inverter (VSI) is shown in figure 4. It consists of four choppers. When IGBTs $\mathrm{Q}_{1}$ and $\mathrm{Q}_{2}$ are turned on simultaneously, the input voltage $\mathrm{Vs}$ appears across the load. If IGBTs $\mathrm{Q}_{3}$ and $\mathrm{Q}_{4}$ are turned on at the same time, the voltage across the load is reversed and is Vs. the wave for the output voltage is shown in figure 5.

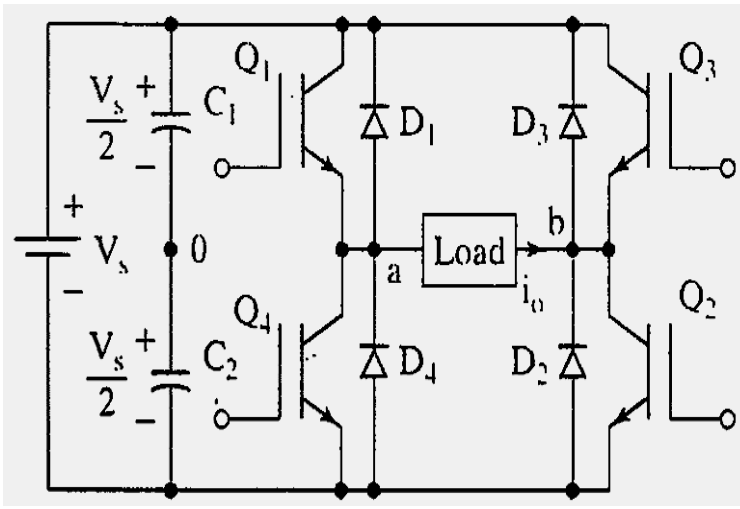

Figure 4. A single phase full wave inverter

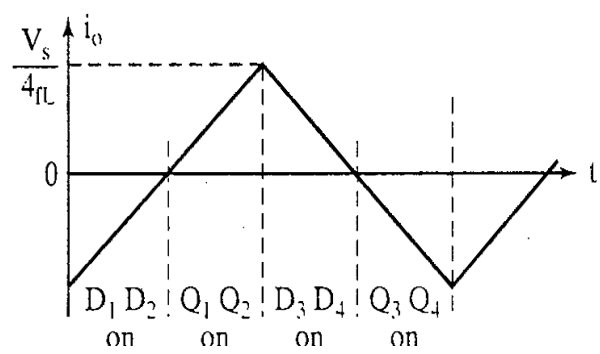

Figure 5. Load current with highly inductive load

Table 1 shows the five switch states. IGBTs $Q_{1}, Q_{4}$ in figure 4 act as the switching devices $S_{1}, S_{4}$, respectively. If two switches: one upper and one lower conduct at the same time such that the output voltage is $\pm V_{s}$, the switch state is 1 , whereas if these switches are off at the same time, the switch state is 0 . Figure 5 shows the load current for highly inductive load.

The rms output voltage can be found from the expression as under

$$
V_{0}=\left(\frac{2}{T_{0}} \int_{0}^{T_{0}} / 2 V_{s}^{2} d t\right)^{1 / 2}=V_{s}
$$

Equation 2.2 can be extended to express the instantaneous output voltage in a Fourier series as

$$
v_{0}=\sum_{n=1,3,5 \ldots}^{\infty} \frac{4 V_{S}}{n \pi} \sin n \omega t
$$

Table 1. Switch State for Single Phase Full Voltage Source Inverter (VSI)

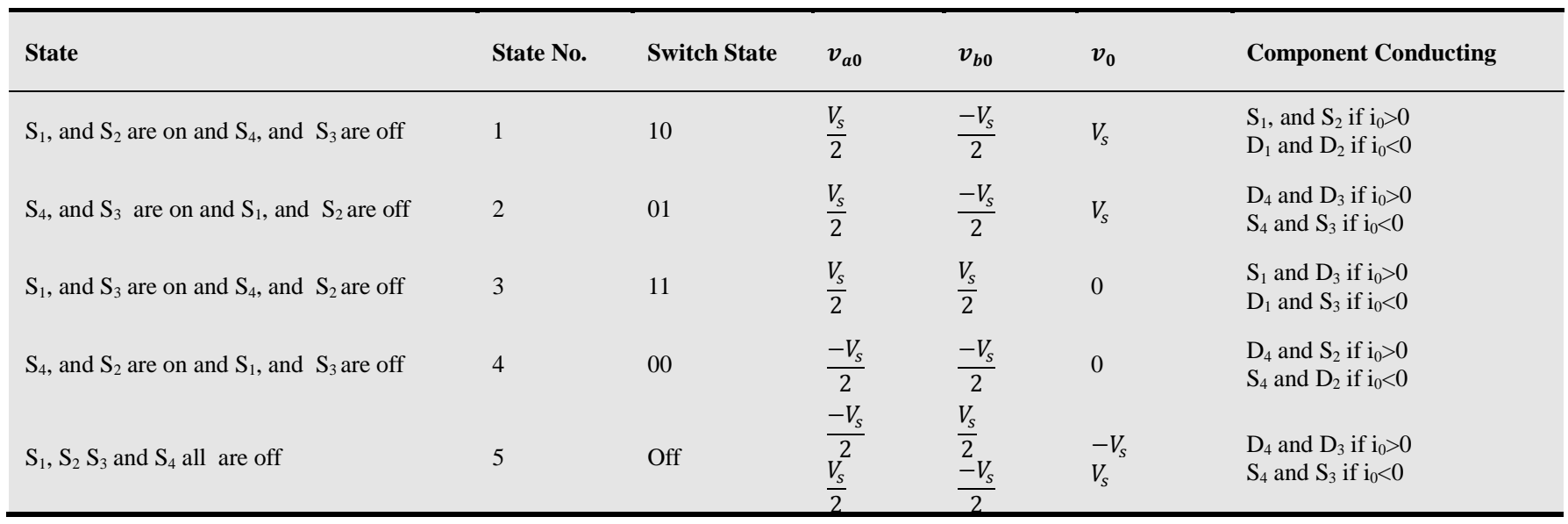

The fundamental rms component of the output voltage is obtained by substituting $\mathrm{n}=1$. Therefore the fundamental voltage is

$$
V_{1}=\frac{4 V_{S}}{\sqrt{2} \pi}=0.90 V_{S}
$$

\section{Simulation}

The entire simulation has been carried out in MATLAB 7.0.1 SIMULINK. Both linear and non linear loads have been considered for open loop control of voltage controlled voltage source inverter. The parameters of the inverter are given in table 2 [2].
Table 2.Parameters of Inverter

\begin{tabular}{llll}
\hline PARAMETER & LABEL & VALUE & UNIT \\
\hline Rated power & - & 3.5 & $\mathrm{kVA}$ \\
Rated output frequency & $\mathrm{F}_{\text {load }}$ & 50 & $\mathrm{~Hz}$ \\
Rated output voltage & $\mathrm{V}_{\text {load }}$ & 230 & $\mathrm{~V}$ \\
Battery voltage & $\mathrm{V}_{\text {batt }}$ & 24 & $\mathrm{~V}$ \\
Battery and lead wire resistance & $\mathrm{R}_{\text {batt }}$ & 30 & $\mathrm{~m} \Omega$ \\
DC filter capacitance & $\mathrm{C}_{\mathrm{dc}}$ & 4 & $\mathrm{mF}$ \\
Inverter Switching frequency & $\mathrm{f}_{\mathrm{sw}}$ & 20 & $\mathrm{kHz}$ \\
Filter inductor & $\mathrm{L}_{\mathrm{f}}$ & 1 & $\mu \mathrm{H}$ \\
Filter inductor Resistance & $\mathrm{R}_{\mathrm{Lf}}$ & 1 & $\mu \Omega$ \\
Transformer turns ratio & $\mathrm{N}$ & 18 & --- \\
\hline
\end{tabular}

The Matlab Simulink model of the single-phase voltage control voltage source inverter is shown in Figure 6. The 
model developed using the Simulink power system blockset, comprises of components such as power electronic devices (full-bridge and rectifier) and elements such as inductors, capacitors and resistors. The DC model used comprises of the battery $\left(\mathrm{V}_{\text {batt }}\right)$ and its respective resistance and lead wire resistance $\left(\mathrm{R}_{\text {batt }}\right)$ as well as the filter capacitor $\left(\mathrm{C}_{\mathrm{dc}}\right)$ and a DC bus current measurement resistor $\left(\mathrm{I}_{\mathrm{dc}}\right.$ measure), which is of the order of micro-ohms as it is only used for DC bus current measurement. The output from the full-bridge block comprises of the filter inductor and its resistance $\left(\mathrm{L}_{\mathrm{f}}, \mathrm{R}_{\mathrm{Lf}}\right)$ and filter capacitor with damping resistor $\left(\mathrm{C}_{\mathrm{f}}, \mathrm{R}_{\mathrm{Cf}}\right)$. Also included is the step-up transformer $\left(T_{x}\right)$. The resistor ' $R_{\text {measure }}$ ' is of the order of micro-ohms and is only used for load current measurement which is similar to ' $\mathrm{I}_{\mathrm{dc}}$ measure.

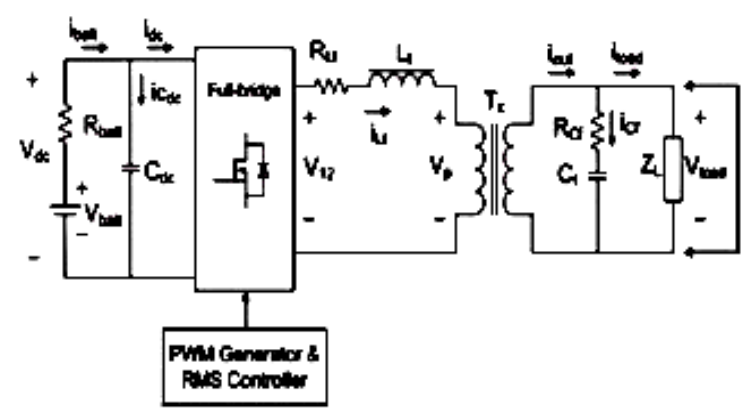

Figure 6. Physical components of single phase VCVSI

A system model showing the physical components of the single-phase Voltage controlled voltage source inverter modeled using Matlab Simulink is shown in Figure 6. This inverter uses a low-voltage DC bus $\left(24 \mathrm{~V}_{\mathrm{DC}}\right)$, which is stepped up to 240VAC using a step-up transformer $\left(\mathrm{T}_{\mathrm{x}}\right)$. The transformer provides galvanic isolation and is a simple solution for the stepping up of a low-voltage DC bus. The DC bus in the model comprises of the battery $\left(\mathrm{V}_{\text {batt }}\right)$, lead wire and battery resistance $\left(\mathrm{R}_{\text {batt }}\right)$, and $\mathrm{DC}$ filter capacitor $\left(\mathrm{C}_{\mathrm{dc}}\right)$. The full-bridge uses IGBT switching devices with the full-bridge output filtered using a low-pass $\mathrm{LC}$ filter $\left(\mathrm{L}_{\mathrm{f}}\right.$ and $\mathrm{C}_{\mathrm{f}}$ ). The inductor filter resistance is represented as $\mathrm{R}_{\mathrm{Lf}}$ with the $\mathrm{LC}$ filter-damping resistor being $\mathrm{R}_{\mathrm{Cf}}$. The load connected to the inverter $\left(\mathrm{Z}_{\mathrm{L}}\right)$ is considered arbitrary (linear and/or nonlinear).

The PWM generator provides the switching signals for the full-bridge. The inverter system modeled with Matlab Simulink was achieved using the power system and standard simulink blocksets. The system was analyzed by sending the required signal to scopes and the workspace, which allowed for analysis and design of the inverter model. The PWM signals for each of the power electronic devices in the fullbridge come from the PWM generator block. This block allows for the switching frequency and number of inverter legs to be selected with all PWM signal multiplexed on a single bus into the full-bridge block (pulses). The input to this block ( $\operatorname{signal}(\mathrm{s}))$ is the sinusoidal reference for the inverter. For the open-loop control, the reference signal (sinusoidal reference) is generated from a generator in Simulink. The simulink models for open- loop control of a linear load and a non-linear load are shown in figures 7 and figure 8 respectively [2 and 3 ].

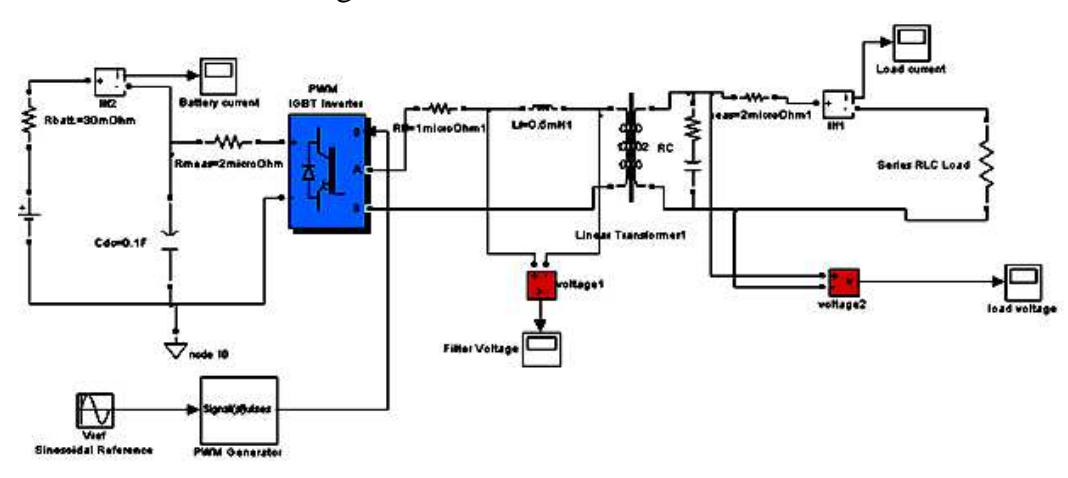

Figure 7. Simulink Model for linear load

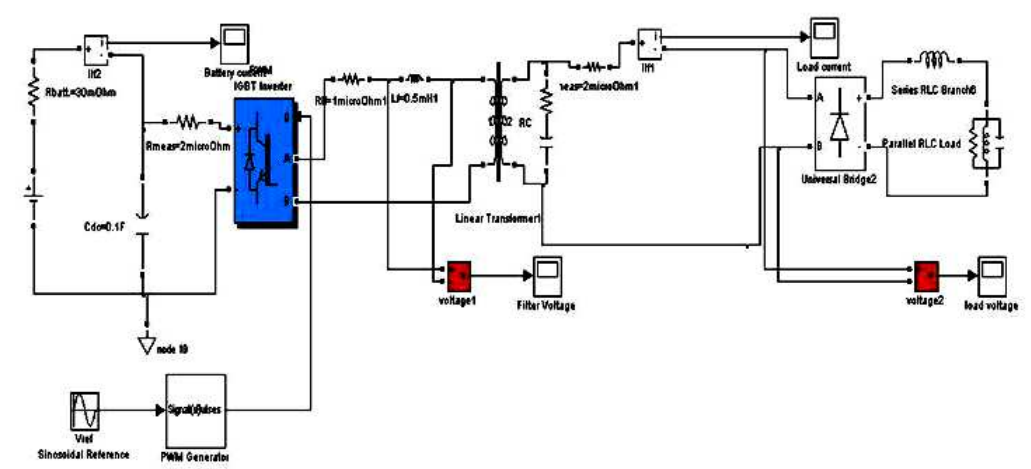

Figure 8. Simulink Model for non-linear load 


\section{Results}

The simulation results for liner and non-linear loads have been obtained and are shown in figures.

\subsection{Linear Load}

Figures 9.1, 9.2, 9.3, 9.4 and 9.5 are the simulation results of the Voltage Controlled Voltage Source Inverter with open loop control having a linear load of $3.5 \mathrm{kVA}$. From the figure 9.1, initially, the load current is maximum, about 6.2 A and settles around $4 \mathrm{~A}$ after 0.33 seconds. The maximum load voltage is $90 \mathrm{~V}$ and it decreases until it settles down at $60 \mathrm{~V}$ as seen in figure 9.2. The filter current is quite high, and is about 3700 A initially and settles around $2000 \mathrm{~A}$. The high in filter current is due to too small impedance offered by the filter inductor $L_{f}$ as seen in figure 9.3. The filter voltage is shown in figure 9.4. The maximum filter voltage is $4 \mathrm{~V}$ initially. It settles to $2 \mathrm{~V}$ after 0.33 second. The battery current settles at $500 \mathrm{~A}$, starting from zero as seen from figure 9.5. In the beginning, when the inverter is switched on, the battery current starts building up. Because of the presence of LC in the circuit, battery current settles to $500 \mathrm{~A}$ after 0.33 seconds. Both, load current and load voltage are similar, except their amplitudes.

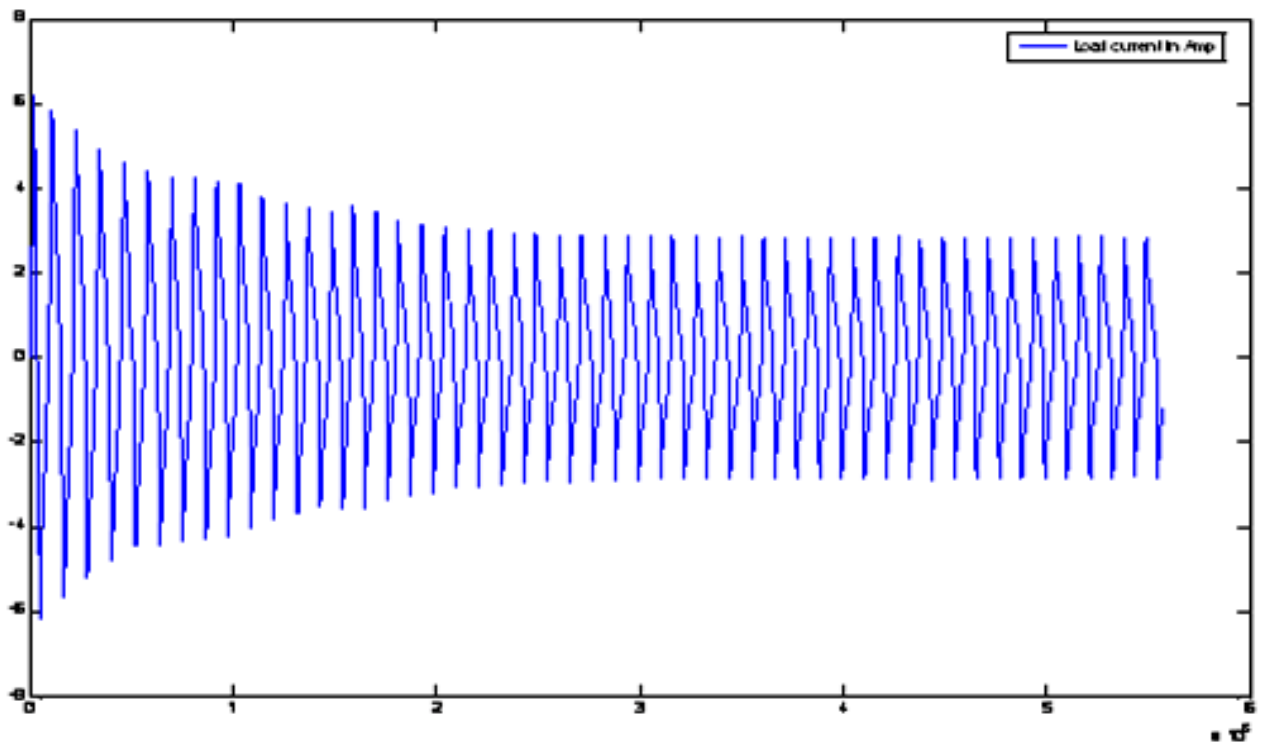

Figure 9.1. Load current

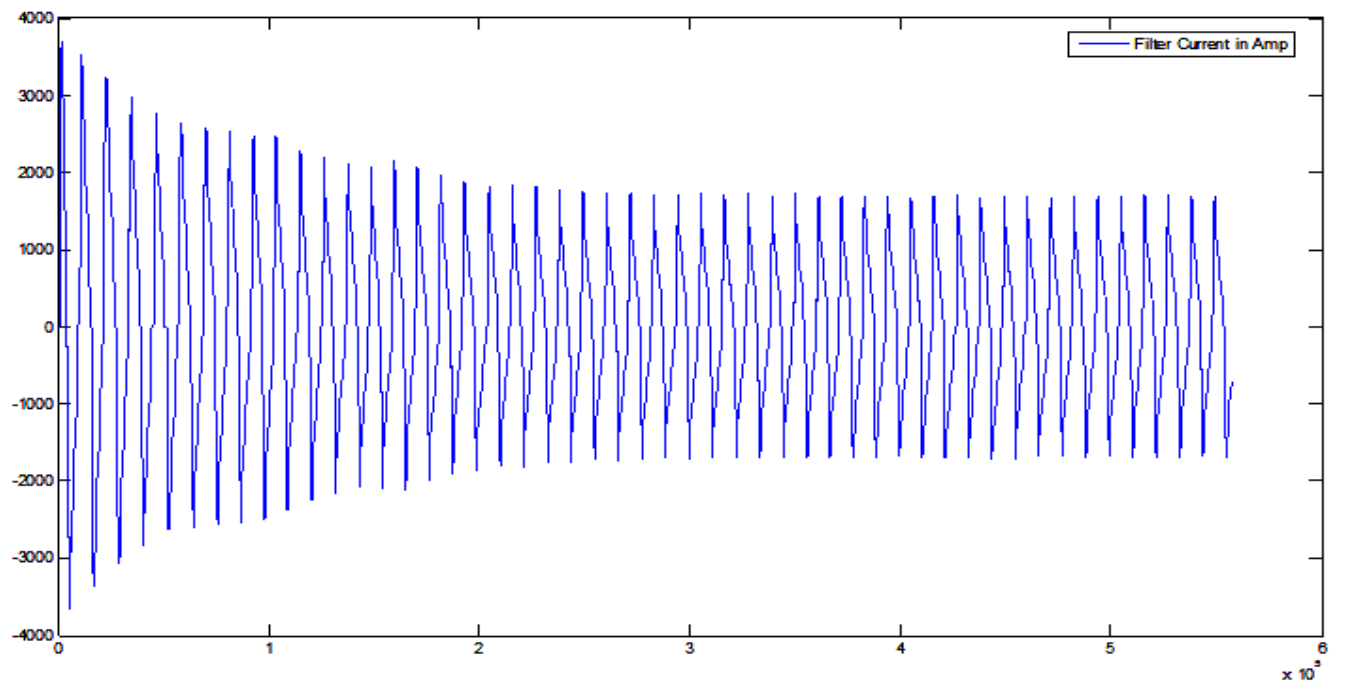

Figure 9.2. Filter current 


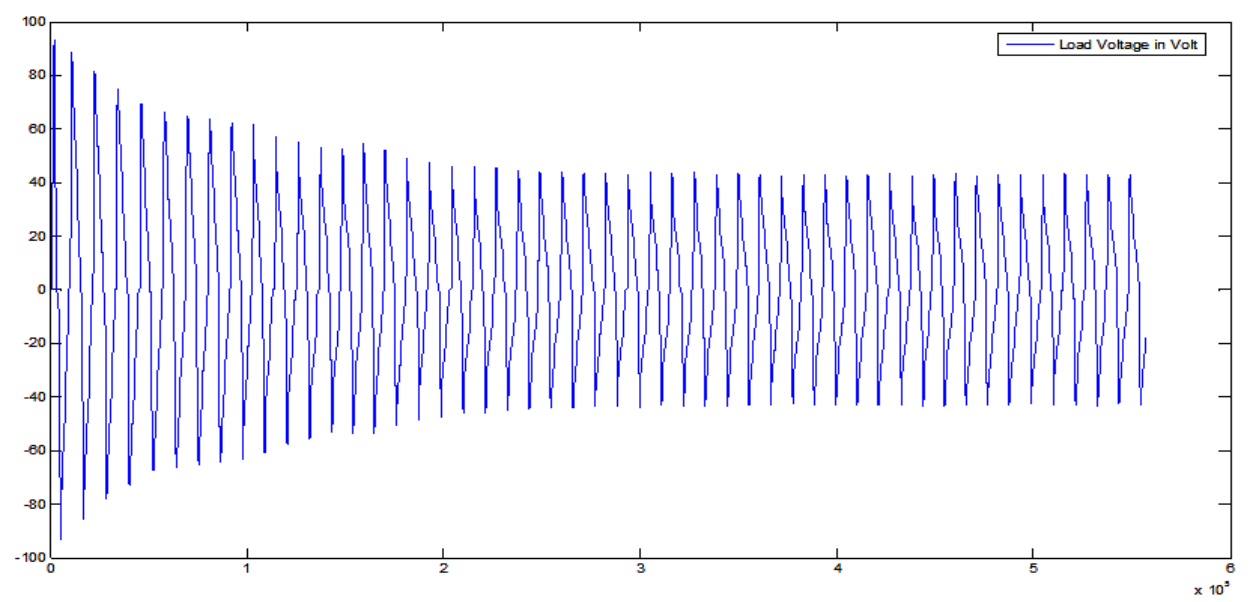

Figure 9.3. Load voltage

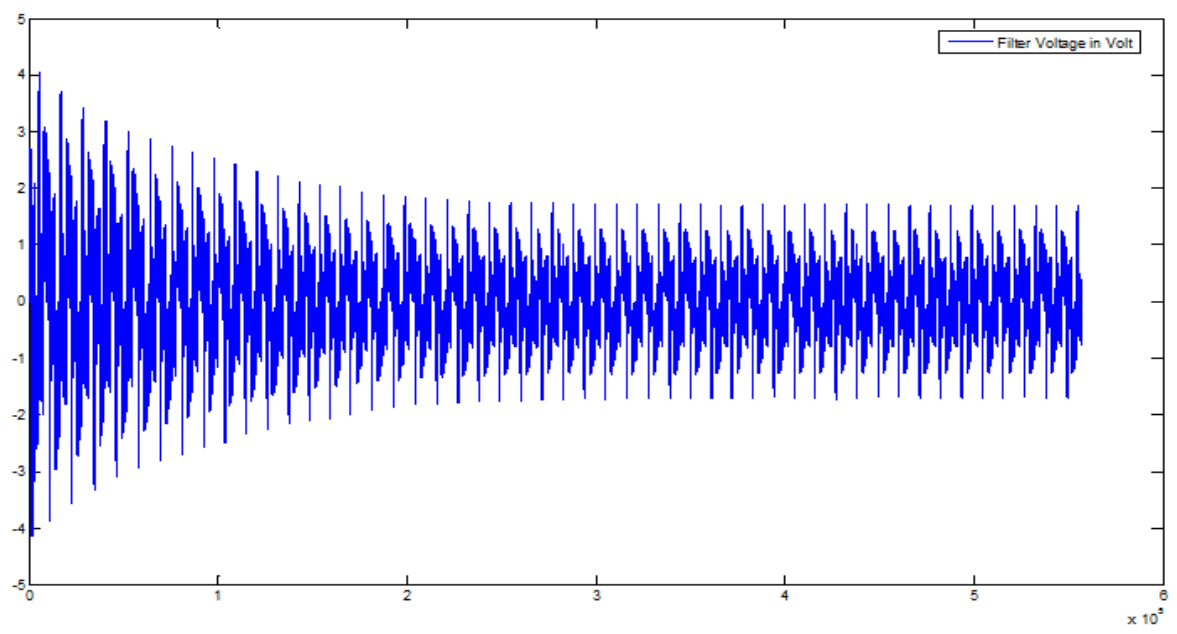

Figure 9.4. Filter Voltage

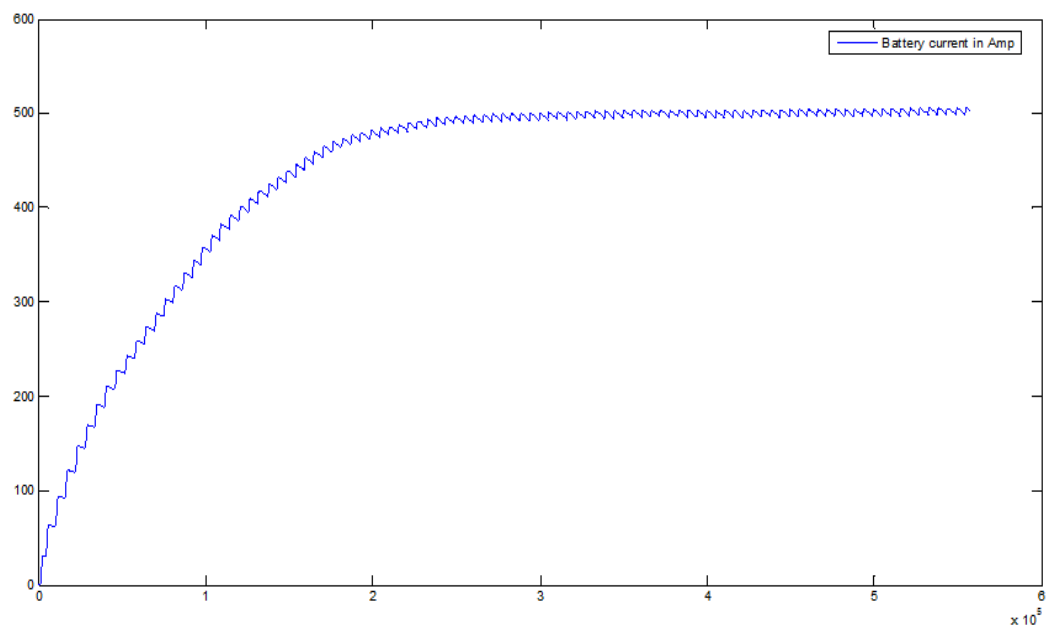

Figure 9.5. Battery current

\subsection{Non-Linear Load}

The various plots obtained through open loop control of a non-linear load are shown in figure 10.1, 10.2, 10.3, 10.4 and 10.5 respectively. As it is seen from the figure 10.1 that the current waveform is not sinusoidal as was in the case of linear load where both load current and load voltage were similar. It is due to non-linearity in the load, hence current wave form is not a complete sinusoidal. The amplitude of the load current becomes constant after 0.03 seconds and is about $1.26 \mathrm{Amps}$. The amplitude of the voltage wave is $60 \mathrm{~V}$ as seen in figure 10.2. The steady amplitude of filter current is $1700 \mathrm{~A}$ and maximum amplitude of the current is $3700 \mathrm{~A}$ as seen in 
figure 10.3. The filter amplitude of voltage is small nearly about $2 \mathrm{~V}$ and the battery current rises from zero to $450 \mathrm{~A}$ in

0.05 seconds as seen in figure 10.4 and figure 10.5 respectively.

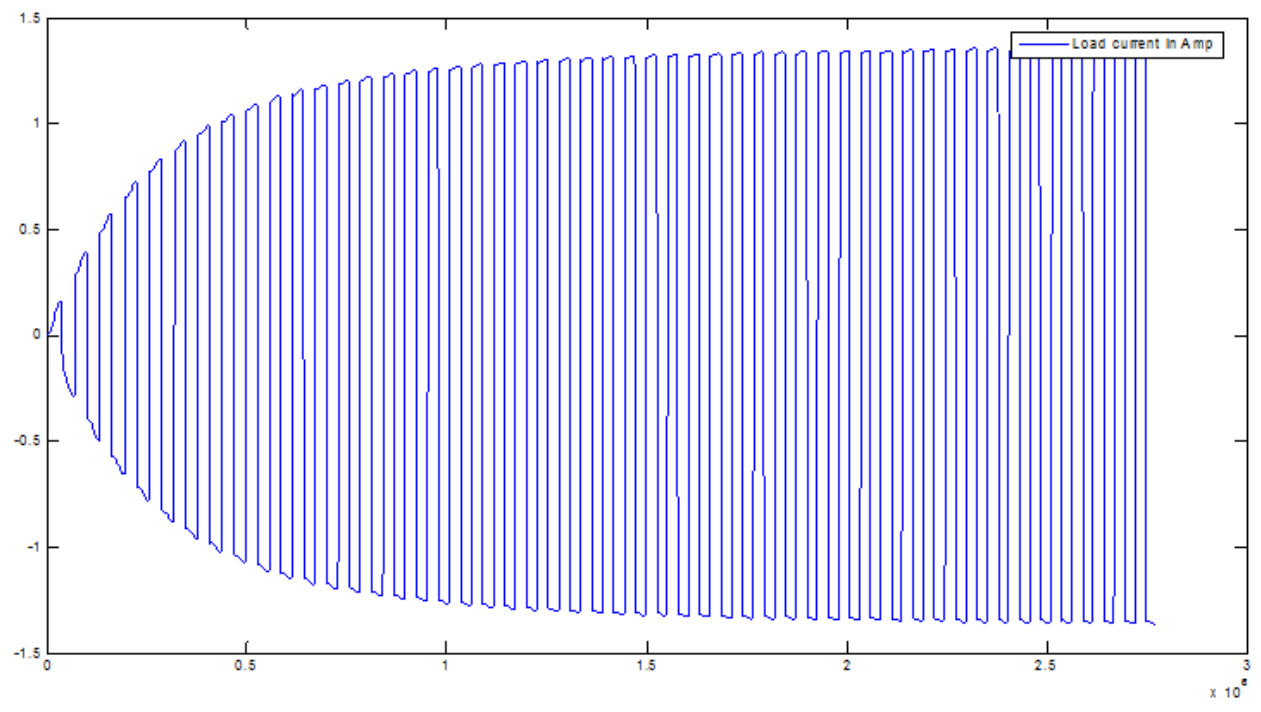

Figure 10.1. Load current

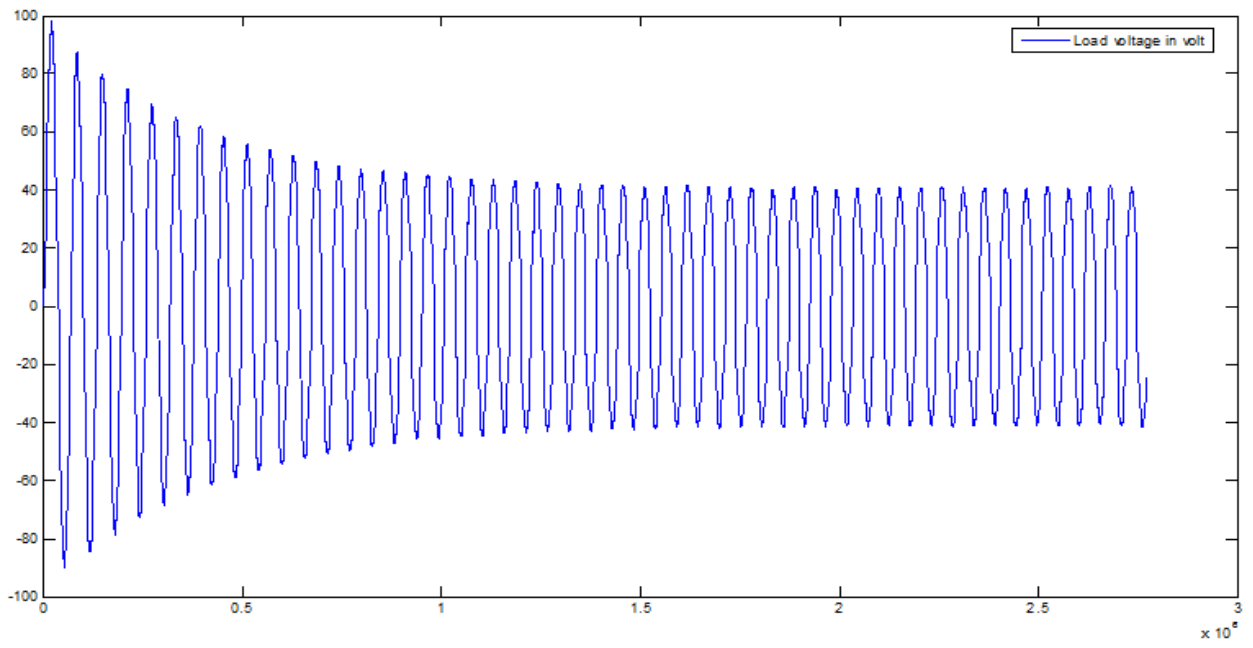

Figure 10.2. Load voltage

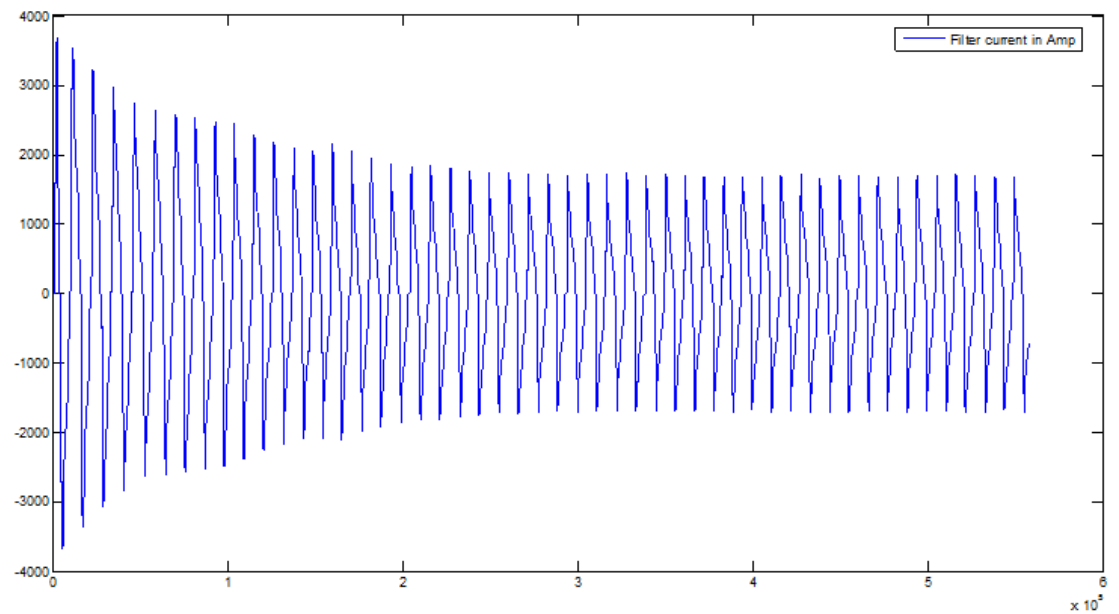

Figure 10.3. Filter current 


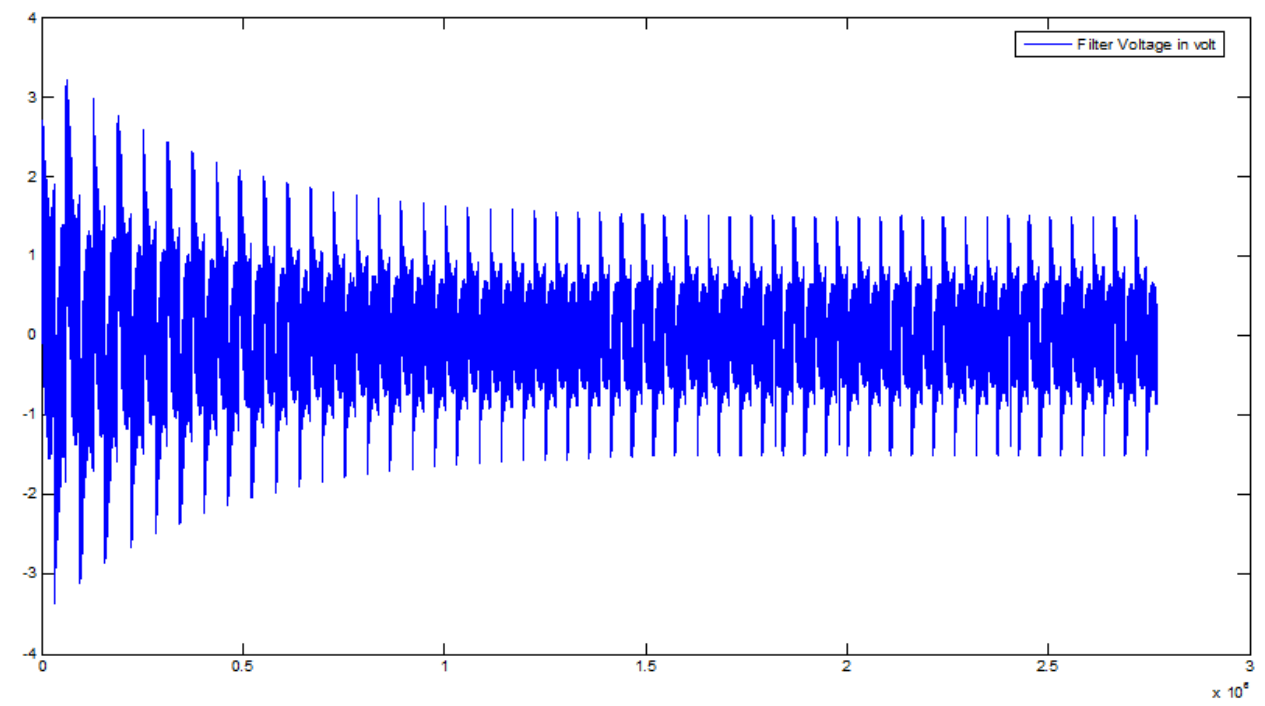

Figure 10.4. Filter voltage

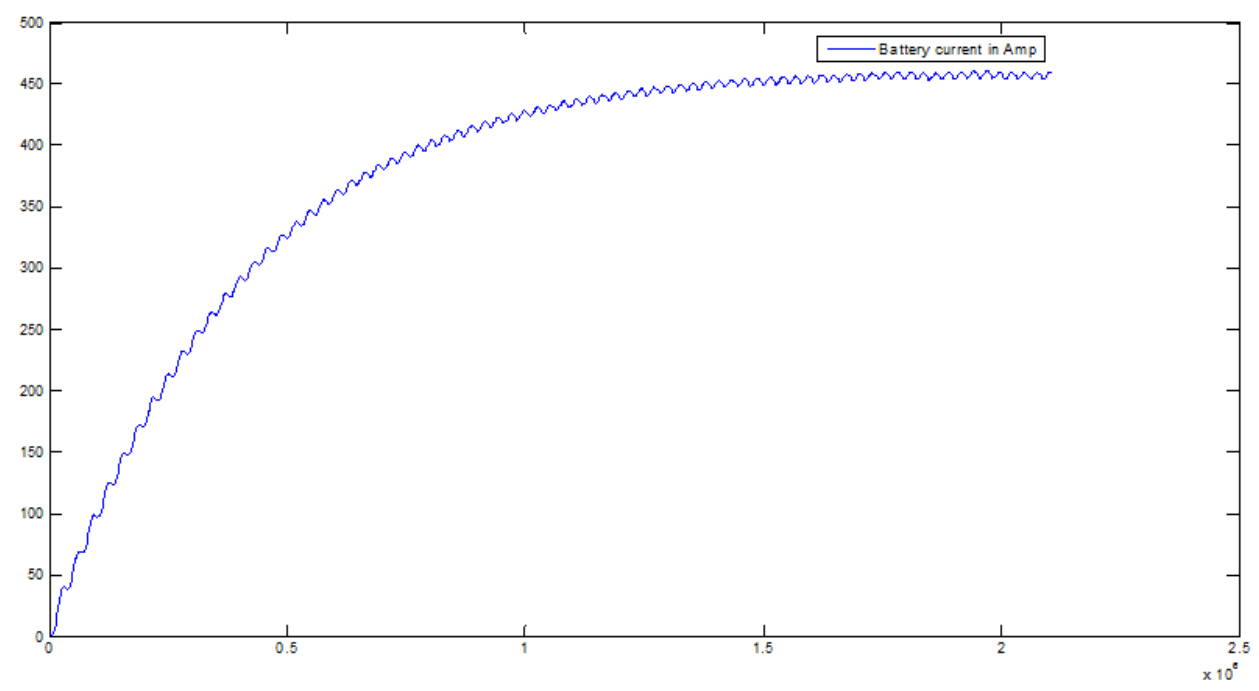

Figure 10.5. Battery current

\section{Conclusions}

A Matlab Simulink model of a single-phase $3.5 \mathrm{kVA}$ Voltage Controlled Voltage Source Inverter with open-loop control has been developed for linear and non-linear loads.

When the nature of load is purely linear, the load current has constant frequency and amplitude after $0.33 \mathrm{sec}$ but this is not so in case of non-linear load, where the load current is not sinusoidal with constant amplitude although there is decrease in steady time. When the load is non-linear, the filter current decreases. There is also decrease of as source current, thus allow to use non-linear load. Irrespective of the nature of load, the filter voltage in both cases is independent of the load current. So it can be concluded that for a open loop system, the non-linear load is preferred.

\section{About the Authors}

Akhilesh Sharma is working as Assist. Prof. in North
Eastern Regional Institute of Science and Technology (under Ministry of Human Resource \& Development, Govt of India), Nirjuli, Arunachal Pradesh, India in electrical engineering department. He did his Master's degree in Power Electronics \& Drives from Madan Mohan Malaviya Engineering College Gorakhpur in 2009 under Uttar Pradesh Technical University, Lucknow, Uttar Pradesh, India.. His area of interest is Neural Networks, Inverter and Electric Drives.

Neeraj Kumar has done post graduation in electrical engineering from Madan Mohan Malaviya Engineering College Gorakhpur in 2009 under Uttar Pradesh Technical University, Lucknow, Uttar Pradesh, India. He is working as Associate professor in DIET, Rishikesh, under Uttarakhand Technical University, Dehradun, Uttarakhand, India. His field of research includes electric drives and control.

Gunjan Gupta is working as assistant professor in Invertis University, Bareilly, India. He has done post graduation from NITTTR, Chandigarh, India. His area of research includes Fuzzy Logics, Instrumentation and Power Electronics. 


\section{References}

[1] N. Mohan, T. M. Undeland, and W. P. Robbins, Power Electronics - Converters, Applications, and Design, 2nd ed: John Wiley \& Sons, Inc., 1995.

[2] "Matlab 6, Release 12.1." Natick, Massachusetts: The MathWorks (www.mathworks.com), 2006. "PSIM Version 7.0." Woburn, MA: Powersim Inc. (www.powersimtech.com), 2006.

[3] M. Trigg, "Digital Sinusoidal PWM Generation using a Lowcost Micro-controller Based Single-Phase Inverter," presented at ETFA 2005, Catania, Italy, 2005.

[4] M. C. Trigg, H. Dehbonei, and C. V. Nayar, "Digital Sinusoidal PWMs for a Microcontroller based Single-Phase Inverter. Part 1: Principles of digital sinusoidal PWM generation," IJE Power electronics and instrumentation hardware, 2005.

[5] H. Dehbonei, M. C. Trigg, and C. Nayar, "A Novel Sinewave Inverter for Harsh Environment," presented at AUPEC 2005, Hobart, Tasmania, Australia, 2005.

[6] M. H. Rashid," Power Electronics circuits, devices, and applications ", Pearson Education India, $3^{\text {rd }}$ Edition 2004. 